\title{
Reduction of TNFR2 Expression in Brain Endothelial Cells in Cerebral Malaria Mice Models after Hyperbaric Oxygen Exposure
}

\author{
Prawesty Diah Utami, Usman Hadi, Yoes Prijatna Dachlan, Guritno Suryokusumo, Loeki Enggar \\ Fitri
}

\begin{abstract}
Tumour Necrosis Factor Receptor 2/ TNFR2 is the main receptor of TNF- $\alpha$ expressed by brain endothelial cells and contributes to Nuclear Factor Kappa Beta/ NFאB activation which induces sequestration of leucocyte cells. The role of hyperbaric oxygen/HBO as a regulator of the inflammatory process can be used as a supportive therapeutic approach in cerebral malaria infection. The research aimed to examine the impact of HBO administration on expression of TNFR-2 in brain endothelial cells of mice infected with P. berghei ANKA. P.berghei ANKA / PbA infected C57BL/6 divided into 3 groups with 13 mice per group: G1 (negative control, normal mice); G2 (positive control; mice infected with $\mathrm{PbA}$ without $\mathrm{HBO}$ ); $\mathrm{G3}$ (treatment group; mice infected with $\mathrm{PbA}$ with $\mathrm{HBO}$ ). Observation of TNFR2 expression using immunohistochemical techniques on the last day of treatment.

Study results revealed that there has been a significant decrease in TNFR2 expression in brain vascular endothelial cells in the group that received $\mathrm{HBO}(p<0.05)$. Exposure to $\mathrm{HBO}$ 2.4 ATA for 10 sessions can prevent cerebral malaria by decreasing TNFR2 expression in vascular endothelial cells of the brain of the mice model.
\end{abstract}

Keywords: Cerebral Malaria, HBO, Plasmodium berghei ANKA, TNFR2.

\section{INTRODUCTION}

Malaria infection is a vector transmitted disease caused $b$ yblood parasite, Plasmodium sp. Number of malaria infections based on WHO data shows 200 million people have been infected and can cause 400 thousand deaths. In the absence of a malaria vaccine and reports of resistance to ACT (artemisinin combination therapy) being the cause of this infectious disease are still a global health problem [1]-[2].

Clinical manifestations of malaria vary from asymptomatic - flu-like disease (in populations living in endemic areas) to clinical manifestations that are less common but fatal and can

Revised Manuscript Received on January 5, 2020.

Dr. Prawesty Diah Utami, Lecturer of Parasitology, Faculty of Medicine, Hang Tuah University, Surabaya, Indonesia.

Dr. Usman Hadi, Professor, Department of Internal Medicine, Faculty of Medicine, Regional Hospital Dr. Soetomo Hospital, Airlangga University, Surabaya, Indonesia.

Dr. Yoes Prijatna Dachlan, Professor, Department of Parasitology, Faculty of Medicine, Airlangga University, Surabaya, Indonesia.

Dr. Guritno Suryokusumo, Professor, Department of Hyperbaric, Faculty of Medicine, Indonesia University, Depok, Indonesia.

Dr. Loeki Enggar Fitri, Professor, Department of Parasitology, Faculty of Medicine, Brawijaya University, Malang, Indonesia. cause death. Complications of severe malaria include severe anemia, metabolic acidosis, respiratory system disorders, multi-organ disorders and cerebral malaria [3].

Cerebral malaria was a malaria complication characterized by decreased awareness or the appearance of neurological disorders (ataxia, seizures, paraplegic, etc.). The emergence of various neurological disorders and decreased awareness of cerebral malaria is associated with the occurrence of excessive inflammatory processes in response to a high degree of parasitemia [4].

Pathogenesis of cerebral malaria involves complex biological processes, one of which is the excessive activity of proinflammatory cytokines TNF- $\alpha$ / Tumour Necrosis Factor Alpha. Proinflammatory cytokine TNF- $\alpha$ has two receptors such as TNFR1 and TNFR2, but previous studies have proven that TNFR2 takes a major part in the development of cerebral malaria in both humans and laboratory animals models. Tumour Necrosis Factor Receptor 2 / TNFR2 was one of TNF- $\alpha$ receptors expressed by endothelial cells, glial cells, and leukocyte cells. Previous studies have shown that human endothelial cells, as well as experimental animals with cerebral malaria show, increased expression of TNFR2. TNFR2 expression is strongly influenced by Interferon Gamma/IFN- $\Upsilon$ released by $\mathrm{T}$ Helper 1/ TH1. Activated monocytes express TNF transmembrane on the membrane surface to bind to TNFR2 in endothelial cells. These bonds will activate Nuclear Factor Kappa Beta/ NFkB to express ICAM-1 which will induce adhesion of PRBC, leukocytes, platelets which will cause obstruction and ischemia of blood vessels and endothelial cell damage [5].

Hyperbaric oxygen / HBO was a systemic action of $100 \%$ oxygen administration with a standard pressure $2-3$ atmospheres absolute (ATA) inside the chamber. Previous studies have shown that the administration of $\mathrm{HBO}$ can reduce the inflammatory process, and $\mathrm{HBO}$ is used for adjuvant therapy of various inflammatory-related diseases such as necrotizing tissue infections, gangrene gas, burns, osteomyelitis and chronic wounds [6]. The administration of $\mathrm{HBO}$ can improve the function of macrophages as the main source of TNF- $\alpha$, where macrophages and monocytes that are exposed to $\mathrm{HBO}$ will produce fewer TNF- $\alpha$ than those without HBO exposure. This decrease in proinflammatory cytokine production is associated with decreased $\mathrm{NFkB}$ activity and increased HO-1 activity[6]-[7]. Based on the above phenomenon, the goal of this study was to examine the impact of $\mathrm{HBO}$

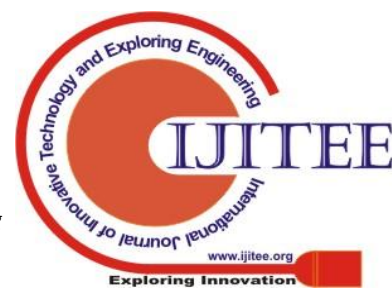


administration in brain endothelial cells mice with cerebral malaria on TNFR2 expression.

\section{MATERIALS AND METHODS}

Research methode was true experimental design in which the research units are assigned randomly to an experimental and control group and the measurement of parameters is done

once in the final phase of treatment. The experimental unit of this study was C57BL/6 female mice aged 7-10 weeks, an average weight of 15-20 grams obtained from PT Indoanilab Bogor which has been declared free of pathogens. The experimental unit will be divided into 3 groups as follows:

1. Group 1 (G1/negative control): 13 mice without $\mathrm{PbA}$ infection and no HBO administration.

2. Group 2 (G2/positive control): 13 mice infected with $\mathrm{PbA}$ without $\mathrm{HBO}$ administration.

3. Group 3 (G3/ treatment group): 13 mice infected with $\mathrm{PbA}$ and administration of HBO 2.4 ATA exposure 3 times 30 minutes $100 \% \mathrm{O}_{2}$ for 10 consecutive days.

The research includes the process of $\mathrm{PbA}$ infection carried out in the clinical parasitology laboratory of the Faculty of Medicine, Universitas Brawijaya Malang; the presentation of $\mathrm{HBO}$ in the Hyperbaric Laboratory of Medical Faculty Hang Tuah University, Surabaya and the reading of the immunohistochemistry / IHC preparations was carried out in the Anatomical Pathology Department of Medical Faculty Airlangga University, Surabaya. The research was also supported by Faculty of Veterinary Medicine's ethics committee at Airlangga University, Surabaya.

\section{A. Mice Models}

The C57BL/6 mice used in this study was the most commonly used cerebral malaria mice model because it has a high susceptibility to P.berghei ANKA infection, clinical manifestation outcomes were similar to human cerebral malaria in terms of neurological symptoms appearance, increased proinflammatory cytokines, increased lactate production, increased endothelial receptors, the occurrence of vasculopathy such as platelet activation, vascular leakage, edema and micro hemorrhage in the brain [8].

The experimental animals were euthanized on day-13 after infection by an anesthetic injection of $1 \mathrm{ml}$ ketamine and $0.5 \mathrm{ml}$ xylazine (dissolved in 0.9 percent normal saline at $8.5 \mathrm{ml})$. This lethal dose is injected intraperitoneally and three times the anesthetic dose $(0.3 \mathrm{ml} / 10 \mathrm{~g}$ body weight $)$ [9]. Brain tissue was drained and soaked in $10 \%$ neutral formalin (BNF) buffered ( $\mathrm{pH}$ 6.5-7.5) immediately. The formalin-to-tissue ratio was 10:1.

\section{B. Plasmodium berghei ANKA Infection Procedure}

The acclimatization phase is carried out for 1 week in a room, food, and drink that has been sterilized by ultraviolet light. Maintenance of blood-stage parasites $\mathrm{PbA}$ stored nitrogen solution and carried out the serial passage on donor mice. The stage of $\mathrm{PbA}$ infection begins by infecting donor mice with $\mathrm{PbA}$ and observing the level of parasitemia up to $15 \%$. Then intracardiac blood samples were taken and diluted with PBS solution twice. Mice were infected with $1 \mathrm{x}$ $10^{6}$ erythrocytes infected with $\mathrm{PbA}$ by intraperitoneal injection. The growth of parasites is observed serially from day 1 to day 12 post-infection. Observation of the level of parasitemia was done by counting the number of infected erythrocytes divided by 1000 erythrocytes multiplied by $100 \%$ using a binocular microscope and Giemsa staining[10].

\section{Hyperbaric Oxygen Administration}

One session of $\mathrm{HBO}$ is 100 percent oxygen administration at 2.4 atmosphere absolute level pressure for 3 times 30 minutes at 5 minute intervals of air (20-21\%) compression[11]. The interval between one session and the next session is 24 hours, and 10 sessions exposure are completed within 10 days.

\section{Immunohistochemical Examination of TNFR2 Expression}

With a $4 \mu \mathrm{m}$ thick incision, brain tissue is cut in the corona plane and stained with hematoxylin-eosin. Stages of immunohistochemical staining are started by washing slides with phosphate saline solution (PBS, $\mathrm{pH} 7.4$ ) for 5 minutes, $3 \% \mathrm{H}_{2} \mathrm{O}_{2}$ for 20 minutes, and PBS for $3 \times 5$ minutes. Using $5 \%$ fetal bovine serum (FBS) and $0.25 \%$ TritonX-100, non-specific protein is blocked and washed with PBS for 5 minutes. Monoclonal antibody TNFR2 incubation (Santa Cruz Biotechnology, catalog number: sc-8041) for 1 hour, accompanied by PBS 3x 5 min washing. The sections are incubated at $25^{\circ} \mathrm{C}$ for 10 minutes with chromogenic diaminobenzidine (DMB), followed by $\mathrm{H} \& \mathrm{E}$ solution and finally rinsed with tap water.

Observation of TNFR2 expression in brain endothelial cells of the brain was observed using an Olympus BX53 microscope connected to an Olympus DP27 camera and computer, $400 \times$ magnification on a 10 field of view, the observations were made by two different people and conducted separately. Interpretation result was made by summing all endothelial cells expressing TNFR2 compared to the total number of endothelial cells observed and multiplied by 100 . The intensity of staining is measured semi-quantitatively by giving a score $(0-3)$ based on cell color gradations as follows;(1)Rating 0: negative;(2) Rating 1: poor staining; (3)Rating 2: moderate staining;(4)Rating 3: heavy staining. Total score $=$ percentage of brown colored cells $\mathrm{x}$ intensity (maximum value of 300 ); the data obtained in the form of ratio data scale[12].

\section{E. Statistical Analysis}

The data in the study were analyzed using multivariate parametric analysis Manova and continued by the post hoc LSD analysis with $\mathrm{p}$ value about 5 percent.

\section{RESULTS AND DISCUSSION}

Development of parasitemia level starts at day- 2 post- $\mathrm{PbA}$ infection followed by administration 10 sessions of HBO exposure from day- 3 to day- 12 post-PbA infection. On the 13th day, the mice were terminated and their brain tissue was taken to make IHC preparations and TNFR2 expression was observed. The picture of observations of TNFR2 expression in the three groups is as follows: 


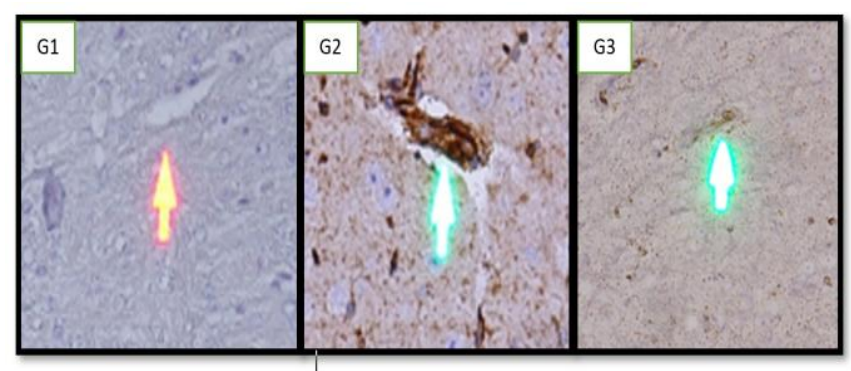

Fig 1. TNFR-2 Expression in Vascular Endothelial Cells in Mice Brain Tissues

Differences in expression of TNFR2 in (G1) Negative Control (G2) Positive Control (G3) Treatment Group. 400 X magnification, Olympus BX53 microscope, 5-megapixel DP27 camera.

In the picture above, the arrow shows TNFR-2 expression marked in brown on the cytoplasm of brain endothelial cells. The results showed the expression of TNFR-2 in the treatment group was lower with a lower intensity than the positive control, but its expression was more numerous and stronger than the negative control group. The results of descriptive analysis and MANOVA test on the immunohistochemical examination of TNFR2 as follows:

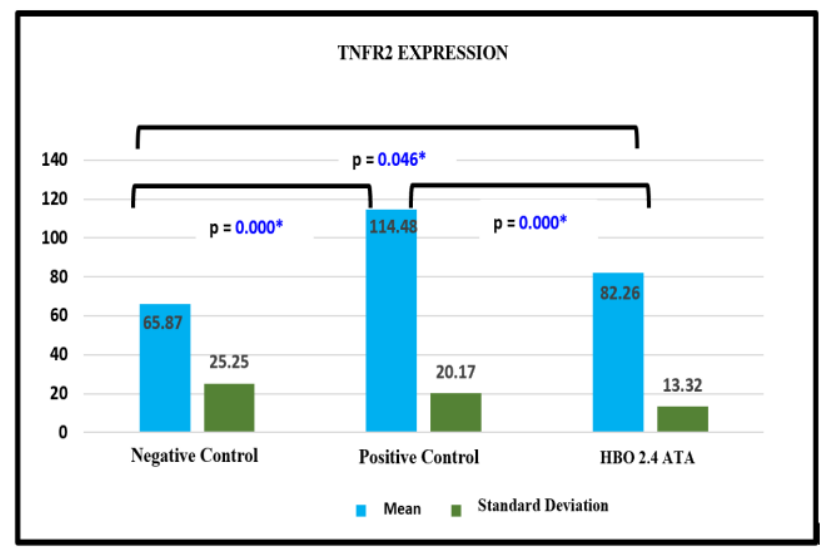

Fig 2. Mean Value and Standard Deviation of TNFR Expression2

The bar diagraph showed that TNFR2 expression in the positive control group had the highest mean and standard deviation; the negative control group had the lowest mean and standard deviation. Statistical analysis showed that TNFR2 expression distinguished significantly between posi tive and negative controls; positive control with the treatment group as well as negative control with the treatment group. (*: indicates a significant post hoc LSD test).

In accordance with the Wah et al findings. (2016), which concluded that cerebral malaria increases the expression of TNFR2 associated with the sequestration of immune cells ( leukocyte cells) that express TNF- $\alpha$ transmembrane to form TNFR2 bonds and induce ICAM-1 expression [5].

In comparison, TNFR1 has a stronger bond in circulation with soluble TNF- $\alpha$, so the rise in circulation TNF- $\alpha$ was not related to the incidence of cerebral malaria [5]. The finding of this research also presented that TNFR2 expression was affected by the rate of parasitemia, increased expression of TNFR2 was followed by increased parasitemia levels. These findings are the same as Yunga et al. study, a significant increase in TNFR1 and TNFR2 and associated with a higher level of parasitemia compared to non-malaria pregnant women [12].

The negative control group showed the lowest expression of TNFR2 and differed significantly from the other groups. This is due to the absence of infection or inflammatory process in this population which causes low TNFR2 expression. The treatment group showed a significant decrease in the expression of TNFR2 relative to positive controls. HBO's mechanism to reduce TNFR2 expression is likely to occur via redox signaling theory, ROS / Reactive Oxygen Species as a second messenger that controls the immune response by reducing proinflammatory cytokine output to prevent severe damage. In the treatment group that received $\mathrm{HBO}$, it would produce more ROS molecules than the control groups. Previous research has shown that intracellular ROS increased after HBO administration, ROS also acts as a second massanger affecting gene expression. ROS may regulate NFkB activity, the relationship between the two is still being debated because some say that intracellular ROS can inhibit NFkB activation, but some argue otherwise[14]. The results of this study prove that ROS decreases NFkB activity which is characterized by a decrease in TNFR2 expression. Decreased rates of parasitemia may also decrease the expression of TNFR2 as a result of decreasing parasite in the circulatory effect on decreasing effector immune cell function, resulting in decreased development of TNF- $\alpha$ cytokine and accompanied by decreased receptor expression, TNFR2[15].

\section{CONCLUSION}

Research results have shown that exposure to $\mathrm{HBO}$ in brain endothelial cells will significantly reduce the expression of TNFR2. HBO's mechanism to reduce the expression of TNFR2 may associated with immune response regulation and decreased parasitemia rates.

\section{ACKNOWLEDGEMENT}

This study was financed by Hang Tuah University's Faculty of Medicine and sponsored by the Clinical Parasitology Lab oratory facilities at Brawijaya University,Hyperbaric Labora tory Faculty Medicine at Hang Tuah University, and Pathology Anatomy Departement Faculty Medicine Airlangga University.

\section{REFERENCES}

1. WHO., (2014). "Status Report on Artemisinin Resistance." Status Report on Artemisinin Resistance. Vol. 13.

2. WHO., (2018). "World Malaria Report 2018." World Health Organization. https://doi.org/ISBN 9789241564403

3. Conroy, Andrea L., Dibyadyuti Datta, and Chandy C. John., (2019). "What Causes Severe Malaria and Its Complications in Children? Lessons Learned over the Past." BMC Medicine 17 (1): 10-13. https://doi.org/10.1186/s12916-019-1291-z.

4. Frevert, Ute, and Adéla Nacer., (2014). "Fatal Cerebral Malaria: A Venous Efflux Problem." Frontiers in Cellular and Infection Microbiology $4 \quad$ (November): 155 https://doi.org/10.3389/fcimb.2014.00155.

5. Wah, Saw Thu, Hathairad Hananantachai, Usanee Kerdpin, Chotiros Plabplueng, Virapong Prachayasittikul, and Pornlada Nuchnoi., (2016). "Molecular Basis of Human Cerebral Malaria

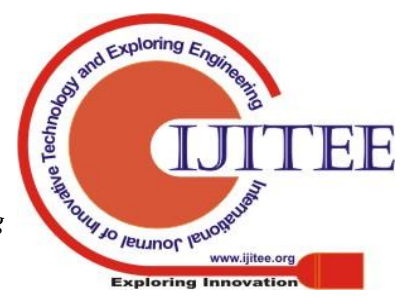


Development." Tropical Medicine and Health 44 (33): 1-7. https://doi.org/10.1186/s41182-016-0033-6.

6. Oyaizu, Takuya, Mitsuhiro Enomoto, Naoki Yamamoto, Kunikazu Tsuji, Masaki Horie, Takeshi Muneta, Ichiro Sekiya, Atsushi Okawa, and Kazuyoshi Yagishita., (2018). "Hyperbaric Oxygen Reduces Inflammation, Oxygenates Injured Muscle, and Regenerates Skeletal Muscle via Macrophage and Satellite Cell Activation." Scientific Reports 8 (1): 1-12. https://doi.org/10.1038/s41598-018-19670-x.

7. Novak, Sanja, Ines Drenjancevic, Rosemary Vukovic, Zoltán Kellermayer, Anita Cosic, Maja Tolusic Levak, Péter Balogh, Filip Culo, and Martina Mihalj., (2016). "Anti-Inflammatory Effects of Hyperbaric Oxygenation during DSS-Induced Colitis in BALB/c Mice Include Changes in Gene Expression of HIF-1 $\alpha$, Proinflammatory Cytokines, and Antioxidative Enzymes." Mediators of Inflammation 2016: 1-19. https://doi.org/10.1155/2016/7141430.

8. Ghazanfari, Nazanin, Scott N Mueller, and William R Heath., (2018). "Cerebral Malaria in Mice and Man." Frontiers in Immunology 9 (September): 1-11. https://doi.org/10.3389/fimmu.2018.02016.

9. Einstein, Medicine College of Albert., (2015). "Recommended Methods of Anesthesia , Analgesia , and Euthanasia for Laboratory Animal Species." In Laboratory Animal, 1:1-12.

10. Somsak, Voravuth, Natsuda Polwiang, and Sukanya Chachiyo., (2016). "In Vivo Antimalarial Activity of Annona Muricata Leaf Extract in Mice Infected with Plasmodium Berghei." Journal of Pathogens 2016: 1-5. https://doi.org/10.1155/2016/3264070.

11. Susilo, Imam, Anita Devi, Azham Purwandhono, and Sunaryo Hadi Warsito., (2017). "Effects of Hyperbaric Oxygen Therapy in Enhancing Expressions of E-NOS , TNF- $\alpha$ and VEGF in Wound Healing Effects of Hyperbaric Oxygen Therapy in Enhancing Expressions of e-NOS , TNF$\alpha$ and VEGF in Wound h Ealing." Journal of Physics 853: 1-8.

12. Punsawad, Chuchard, Yaowapa Maneerat, Urai Chaisri, Kwannan Nantavisai, and Parnpen Viriyavejakul., (2013). "Nuclear Factor Kappa B Modulates Apoptosis in the Brain Endothelial Cells and Intravascular Leukocytes of Fatal Cerebral Malaria Nuclear Factor Kappa B Modulates Apoptosis in the Brain Endothelial Cells and Intravascular Leukocytes of Fatal Cerebral Malar." Malaria Journal 12 (1): 1 https://doi.org/10.1186/1475-2875-12-260.

13. Zhou, Quan, Guoyang Huang, Xuhua Yu, and Weigang Xu., (2018). “A Novel Approach to Estimate ROS Origination by Hyperbaric Oxygen Exposure, Targeted Probes and Specific Inhibitors." Cellular Physiology $\begin{array}{llll}\text { and } & \text { Biochemistry } & 47 & \text { (5): }\end{array}$ https://doi.org/10.1159/000491061.

14. Blaser, Heiko, Catherine Dostert, Tak W. Mak, and Dirk Brenner. (2016). "TNF and ROS Crosstalk in Inflammation." Trends in Cell Biology 26 (4): 249-61. https://doi.org/10.1016/j.tcb.2015.12.002.

15. Tassi Yunga, Samuel, Audrey Davidson Thévenon, Rose Gana Fomban Leke, and Diane Wallace Taylor., (2016). "Soluble Tumor Necrosis Factor- $\alpha$ Receptor 2 in Urine Is a Potential Biomarker for Noninvasive Diagnosis of Malaria during Pregnancy." Open Forum Infectious Diseases 3 (2): 1-8. https://doi.org/10.1093/ofid/ofw084.

\section{AUTHORS PROFILE}

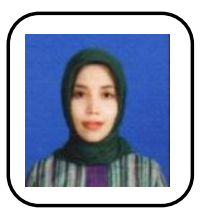

Prawesty Diah Utami, dr., MKed, Lecturer of Parasitology at Faculty of Medicine, Hang Tuah University Educational details: General practitioner at the Faculty of Medicine Airlangga University Surabaya (2003); Masters of Medicine at the Faculty of Medicine Airlangga University Surabaya (2010); Doctoral Program at the Faculty of Medicine Airlangga University Surabaya (2019). Publication : The Effect of Sargassum duplicatum extract on SGPT level in Rattus norvegicus infected by Plasmodium berghei ( 2019; Bali Medical Journal Vol.08;No 02; pp.454 - 456); Protection of Renal Function by Hyperbaric Oxygent during Plasmodium berghe ANKA Infection (2019; ChemTech Journal Vol.13; No. 01; pp 69-74. The fields studied are infectious diseases, immunology, parasitic disease, malaria therapy and prevention

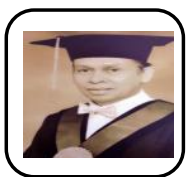

Prof.Dr.dr.Usman Hadi, dr, Sp.PD KPTI

Professor in the Department of Internal Medicine Regional Hospital Dr. Soetomo Hospital-Faculty of Medicine, Airlangga University. Educational details : General practitioner at the Faculty of Medicine Airlangga University Surabaya (1981); Specialist in Internal Medicine at the Faculty of Medicine Airlangga University Surabaya (1990); Doctor Infectius Diseases at Leiden University, Netherlands (2009); Consultant on Tropical Diseases and Infections: Collegium of Internal Medicine (2011). Publication : Expression Of Four Cytokine/Chemokine Genes In Peripheral Blood Mononuclear Cells Infected With Dengue Virus (2019; Indonesian Journal of Tropical and Infectious Disease 7(4).pp 75-78); Association Between Neopterin Levels
And Outcome In 30 Day HIV/AIDS Naive Patients (2019; Biomolecular and Health Science Journal 2(2).pp 102-106). The fields studied are molecular biology, infectious diseases, , antibiotic resistance and ESBL

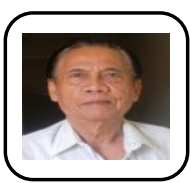

Prof. Dr. Yoes Prijatna Dachlan dr., M.Sc, Sp.ParK Professor in the Parasitology Department Faculty of Medicine, Airlangga University Educational details : General practitioner at the Faculty of Medicine Airlangga University Surabaya (1972); Magister of Parasitology at the Faculty of Medicine Airlangga University Surabaya (1977); Master Program at Amsterdam University (1980); Doctoral Program at the Faculty of Medicine Airlangga University Surabaya (1990); Publication : Overview Of Nuclear Factor-Kb (Nf-Kb) And Non Structural Protein 1 (Ns1) In Patients With Dengue Fever In Premier Hospital, Surabaya (2019; Indonesian Journal of Tropical and Infectious Disease 7 (5). pp 109-113).The fields studied are infectious diseases, immunology, parasitic disease, malaria therapy and prevention.

Prof. Dr Mohammad Guritno Suryokusumo dr., SMHS, DEA

Professor in the Hyperbaric Department Faculty of Medicine, Indonesia University Educational details : General practitioner at the Faculty of Medicine Indonesia University Surabaya (1978); Specialite Medecine Hyperbare et Subaquatique at the Faculty of Medicine De Lille II Franch (1990); D'Étude et Profonde DEA at Faculty of Medicine University of Aix

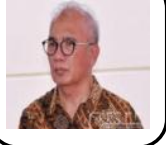
Marseiller II, France (1992); Doctoral Program at Faculty of Medicine De Lille II Franch (1994). Publication : Effect of Hyperbaric Oxygen Therapy to IFN $\gamma$ and TNF $\alpha$ Expression In Pregnant Rattus Novergicus Infected with Tachyzoite of Toxoplasma gondii (2019;Bali Medical Journal 8(1).pp 94-100); Hyperbaric Oxygen Effects Towards SIRT1 Level In Sprague dawley With Endothelial Dysfunction By High-Cholesterol Diet (2018; Bali Medical Journal 7(2).pp 535 -5380). The fields studied hyperbaric treatment, molecular biology, infectious and metabolic disease.

Prof. Dr Loeki Enggar Fitri, dr, M.Kes, Sp.ParK .

Professor in the Parasitology Department Faculty of Medicine, Brawijaya University Educational details : General practitioner at the Faculty of Medicine Brawijaya University Malang (1990); Masters in Health Sciences Society (Tropical Medicine), Postgraduate Program, Gadjah Mada University

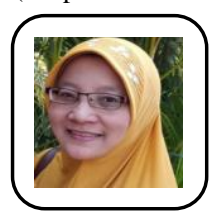
Jogjakarta (1997); Doctor of Medicine, Postgraduate Programs at the Faculty of Medicine Brawijaya University Malang (2004); Clinical Parasitology Specialist from the Clinical Parasitology Collegium Indonesia (2004). Publication: Effect of Metabolite Extract of Streptomyces hygroscopicus subsp. hygroscopicus on Plasmodium falciparum 3D7 in Vitro (2019; Iranian Journal of Parasitology 14(3).pp 444-452); Antimalarial Properties of Isoquinoline Derivative from Streptomyces hygroscopicus subsp. Hygroscopicus: An In Silico Approach (2020; Biomedical Research Internationalpp 1-15). Achievement: Winner of Merck - i3L Life Science The award. Merck and Indonesia International Institute for Life Sciences(i3L) (2016). The fields studied are infectious diseases, immunology, parasitic disease, malaria therapy and prevention. 